\title{
IMPROVED PERFORMANCE OF BELT CONVEYOR-FEEDER
}

\author{
Vitaly Krupenin $^{1,2}$, George Nerubenko ${ }^{3}$, Dmytriy Gurevych ${ }^{4}$ \\ ${ }^{1}$ Mechanical Engineering Research Institute of the Russian Academy of Sciences, Russia; \\ ${ }^{2}$ Moscow Polytechnic University, Russia; ${ }^{3}$ NER*MAR Limited, Canada; \\ ${ }^{4}$ Mega Automation Inc., Canada \\ krupeninster@gmail.com,optimalproject@hotmail.com,dgurevych@mega-automation.ca
}

\begin{abstract}
The work of the belt conveyor-feeder is accompanied by harsh vibrations during operation in the agricultural environment. The most critical area is the discharge point, where the products leave the belt. The vibrations reduce the accuracy of the automatic product handling process. It was necessary to solve three interconnected problems of the discussed conveyor: accurate automatic determination of the exit product position, reduction of intensive vibrations and proper usage of damped vibration energy. The example of an automatic system for robotic handling and / or manipulating of the exit objects (products) includes a feeding belt conveyor, laser vision sensor arrays, operational arm and vibration energy harvesting dampers. Transported products (transporting objects, which are placed in the feeding transporter) must be picked up (or relocated, or reloaded, etc.) by the controlled arm. The arm's operation action must provide fast performance with perfect accuracy or minimal energy consumption. The obtained information from a laser vision sensor system is inputting to the computerised device, where several procedures are executed. First of all, the speed of the fed objects is determined, and that value of the immediate speed is the governing magnitude to increase / decrease the speed of the drive motor. Secondly, the current position of the product is determined and the necessary commands are formulated to the arm. The third procedure allows form the tuning signals for vibration energy harvesting dampers. The vibration energy harvesting dampers are developed by the authors and installed at the exit of the conveyor. Such installation configuration gives the opportunity to eliminate vibrations at the discharge area and convert the damped vibration energy into useful electrical power. The theoretical modeling was verified by operational experiments. The test results prove the concept proposed in the study and confirm the efficiency of the introduced systems for optimizing of the belt conveyor-feeder operation.
\end{abstract}

Keywords: belt conveyor-feeder, vibration energy harvesting damper.

\section{Introduction}

The influence of severe vibrations must be reduces during operation of the belt conveyor-feeders. The discharge area of the conveyor is the most critical region where vibration suppression is needed. The robotic arm $[1 ; 2]$ is operating at this area, so it is very important to provide all necessary measures for ideal operation. Such measures have to secure fast performance of the belt conveyor-feeder (equipped by electromechanical robotic system) with a perfect accuracy or minimize the system energy consumption. The study of vibration suppression combined with parallel generation of electrical power (energy harvesting) using suppressed vibrations is presented. The present technology is widely using the energy harvesting units having a certain oscillating weight allowing (in parallel to vibration mitigation) capture, convert and transfer some amount of the wasted power, however, the authors would concentrate on their own R\&D [3-6]. The authors invented and developed Vibration Energy Harvesting Dampers (VEHD) consisting of a tuned mass damper (TMD) and an alternator or generator of electricity. The specific of the proposed VEHD is to provide self-tuning to dampen harmonics over a wide interval of fluctuated frequencies using the control system of TMD. The purpose of this study is to demonstrate the benefits of VEHD implanting into the belt conveyor-feeder system for rising the operation efficiency and keeping high accuracy of the arm functioning.

\section{Analysis of the developed system}

Major schemes and functional components of the proposed electromechanical system were synthesized in [1-6]. It is necessary to point out that the proposed system is a sort of universal one. The developed approach is applicable in various industries, like agriculture (as discussed here), metal plate packing and handling, furniture sheets cut out and shaping, and so on. The proposed approach allows to take into an account the inertia forces, aerodynamic resistance, mechanical properties of handling materials and configurations, etc. Such approach gives the opportunity to provide fast performance with perfect accuracy or minimize the energy consumption. A schematic composition of the proposed system is in Fig. 1. 
The belt conveyor-feeder 1 has the transporting load 2 (bins, bags, sheets, plates, boxes, etc) on its working surface at the discharge area. The arm 3 has to capture load 2 (lift up/relocate/reload/or to do something else) in accordance to the required technological program. An accelerometer 4 (which could measure the vibrations in 3D) is located in the discharge area of the considered belt conveyorfeeder. The laser vision system 5 is sending its information to the data analyzing and movement planning unit 6.

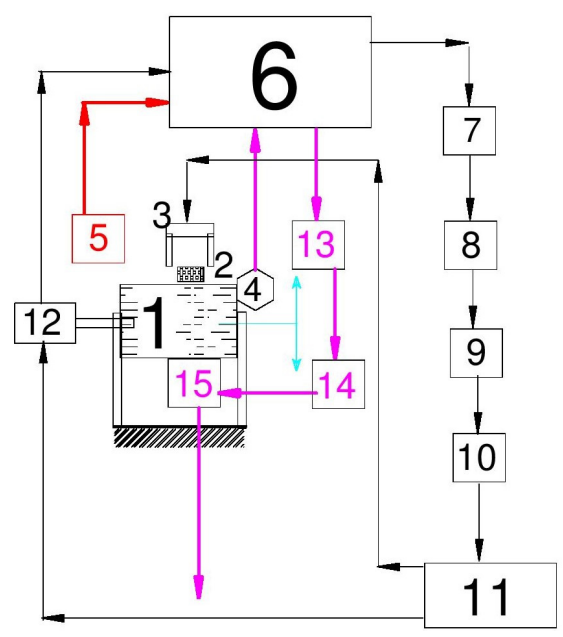

Fig. 1. Graphical presentation of system general composition

One stream of signals from unit 6 is going to unit 7 for formulation of the arm movements. A signal from unit 7 is coming to block 8 for transformation of the arm's coordinates and then going to unit 9 for interpolation. After that a signal from unit 9 is running to unit 10 for program correlation. Unit 10 delivers the signal to the actuator 11 serving the arm 3 and the conveyor's motor 12 . The purpose of the described subsystem is to increase the accuracy of the arm operation. Here the authors must note that the presented chain is a general one: some units could be combined; other units could be split into more detailed components. However, the main logic is directed in it.

The signal sent by the accelerometer 4 is treated in unit 6 and then goes to the commander 13, where the commands are built for the actuator 14. The actuator 14 is servicing the VEHD 15, which is suppressing the conveyor vibrations and generates electrical power that is directing or to a separate source of energy to the grid (not shown in Fig. 1).

It is obvious that vibrations of the conveyor are reducing the accuracy of the subsystem 5-6-7-8-910-11-3/12 operation. Hence, the suppression of undesired conveyor's vibrations is an effective tool for efficiency raise from all points of view.

The conveyor's vibrations have a permanent source like motor and other sources having exploitation nature. The electric drive motor is of $3.7 \mathrm{~kW}$ (see Fig. 2), providing for conveyor a maximum speed of transporting as $0.3 \mathrm{~m} \cdot \mathrm{s}^{-1}$.

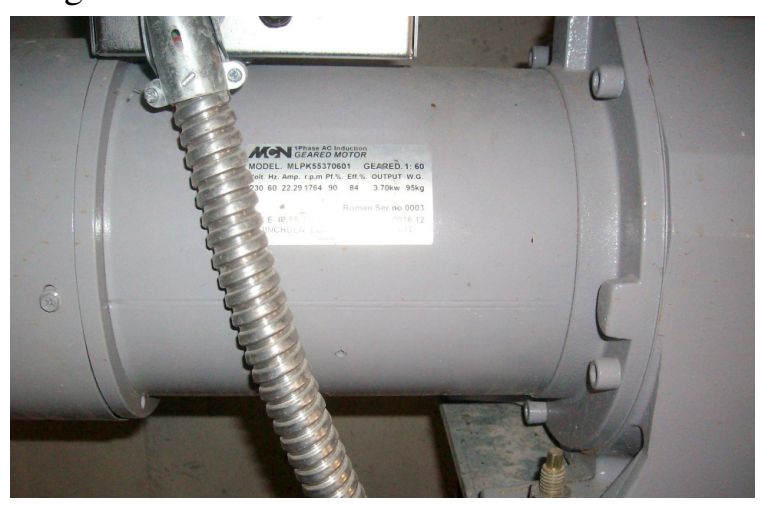

Fig. 2. Conveyor motor

Let us consider for basic explanation the simplest one-dimensional version of VEHD (see Fig. 3) Assume that an object (conveyor) could be modelled by a one-degree-of-freedom system having the 
mass $M$, springing element with the stiffness coefficient $k_{0}$ and viscous friction coefficient $b_{0}$. The conveyor is vibrating along the coordinate axis $X$ as shown in Fig. 3, so, the conveyor's movement coordinate is $X(t)$, where $t$ is the time.

The body 1 of VEHD is attached firmly to the object. VEHD consists of two major parts: a tuned mass damper and alternator. The outer casing of VEHD is firmly attached to the conveyor, and the mass of the casing is included in $M$. TMD $\mathrm{m}$ is connected to the casing by means of springs having the stiffness $k_{1}$ and the viscosity factor $b_{1}$. The mass $\mathrm{m}$ is vibrating in the same direction as the mass $M$. The coordinate of vibrations of $m$ is $x(t)$. It is shown in [3;4] that the highest effectiveness of VEHD could be reached, when $k_{1} / m=\omega_{0}^{2}$ is adjusted to variable external force frequency $\omega$, or $k_{1} / m=\omega^{2}$, however, a special control device must be used in this case providing measuring of the changing values $\omega$ and adjusting the stiffness coefficient of the spring $k_{1}$. In this case the magnitudes of $k_{1}$ would be variable. The diagram layout of that control device is shown in Figure1 by the "magenta" subsystem 4-6-13-14-15.

The electromagnetic subsystem is the inducing current $\mathrm{i}$, and $\mathrm{L}$ is the inductance, $R$ is electrical resistance, where $R_{\mathrm{c}}$ is the coil resistance and $R_{\mathrm{d}}$ is the load resistance, and $R=R_{\mathrm{c}}+R_{\mathrm{d}}$.

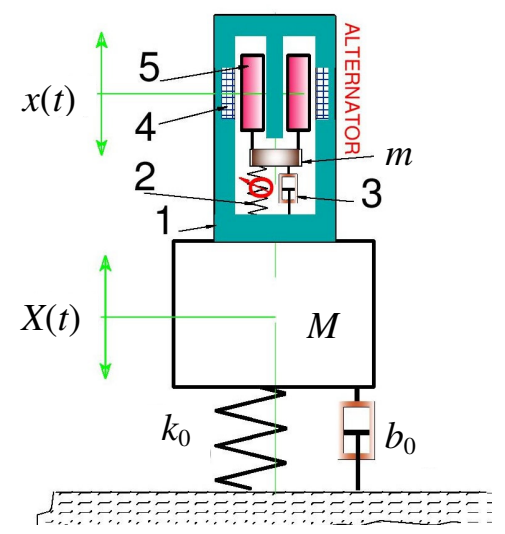

Fig. 3. One-dimensional VEHD

Assume that the external excitation forces could be presented by the term $H \sin (\omega t)$, where $H$ is the amplitude of the external force and $\omega$ is the frequency. The system "VEHD and one-degree-offreedom object" dynamics are described by a system of the ordinary differential equation (see, for instance $[3 ; 5])$

$$
\begin{gathered}
M \ddot{X}+b_{1}(\dot{X}-\dot{x})+j \omega^{2}(X-x)+b \dot{X}+k X=H \sin \omega t, \\
m \ddot{x}-b_{1}(\dot{X}-\dot{x})-j \omega^{2}(X-x)+F i=0, \\
L \dot{i}+R i-F(\dot{x}-\dot{X})=0
\end{gathered}
$$

where $F$ - linkage factor.

The linkage factor could be determined in most cases as $F=B L_{\mathrm{s}}$, where $B$ is the field flux and $L_{\mathrm{s}}$ is the characteristic size.

The system of equations (1) - (3) includes specific features: a) automatic frequency tuning $\omega_{0}=\omega$, and $b$ ) the link between vibrations of the tuned mass damping subsystem and dynamic behaviour of the current generating subsystem (equation (3)). It gives a possibility to be focused on the dynamic properties of TMD coupled to an alternator.

\section{Results and discussion}

It was decided to make the preliminary vibration test for determination of the possible resonances in the conveyor's discharge area. The tests were done in the frequency range $0-100 \mathrm{~Hz}$ for vertical vibrations. One visible spike of $1.1 \mathrm{~mm}$ at $10.8 \mathrm{~Hz}$ was registered. All other amplitudes at other frequencies were negligible, so not worth considering. Hence, the accuracy of the arm operation would be dictated partially by this vibratory issue: the position of the transported product should be "fretted", deviated from the central point periodically in the range of $\pm 1.1 \mathrm{~mm}$. The discovered situation gives an 
opportunity to build a one-degree-of-freedom model of a conveyor and use the equation system (1) (3) for dynamical study of the total object.

Based on these results, received data and using the equation (1) it is possible to model the theoretical amplitude-frequency characteristic of the object vertical vibrations (green solid curve) as shown in Fig. 4. There is the abscissa axis for frequencies in $\mathrm{Hz}$, and the ordinate axis for amplitude values (in millimetres). The amplitude - frequency characteristic in Figure 4 presents that the peak of the amplitude (resonance) of $1.092 \mathrm{~mm}$ is measured at frequency $10.8 \mathrm{~Hz}$, so one can state that the built model reflects successfully the real dynamics.

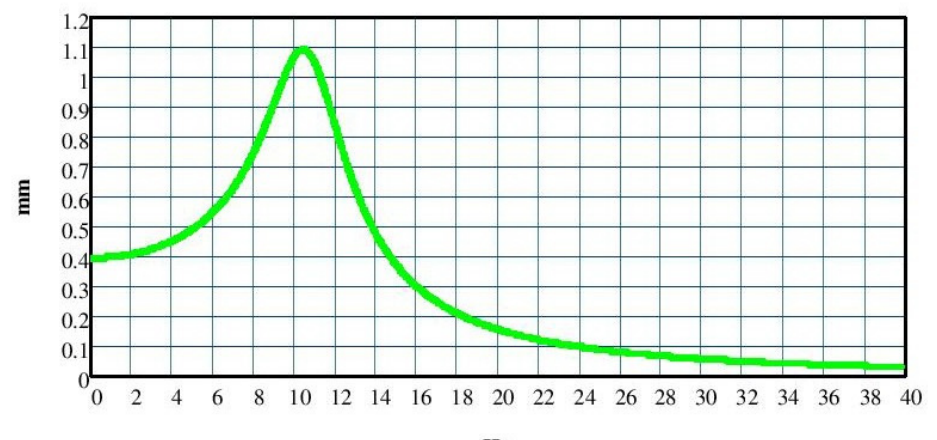

$\mathrm{Hz}$

Fig. 4. Theoretical amplitude-frequency characteristics for examined conveyor

The received parameters allow select the design data for VEHD. Let us remember that the main purpose of VEHD is to satisfy two conditions: 1) reduction of the heaving levels, 2) generation of additional electrical energy due to heaving mitigation. After several probes it was decided that the designed movable mass m of TMD would be $279 \mathrm{~kg}$. The system of equations (1) - (3) was used for determination of the main parameters of VEHD, keeping in mind that $k_{1} / m=\omega^{2}$ and numerical relationships of $[3 ; 4]$ for calculation of the alternator parameters. Finally, the amplitude-frequency characteristics of the considered conveyor-feeder with implanted VEHD could be built (see Fig. 5) exploiting the system of differential equations (1) - (3). The green curve still reflects the dynamical behaviour of the conveyor without installed VEHD, and this curve coincides with the green curve in Figure 4 (the system of coordinates in Fig. 5 is similar to the system of coordinates in Fig. 4). The blue dotted curve in Figure 5 stands for the damped vibrations of the conveyor when VEHD is installed. The maximum damped amplitude (according to the blue dotted line) is $0.585 \mathrm{~mm}$ at $7.7 \mathrm{~Hz}$, and the amplitude at the original resonance point $(10.8 \mathrm{~Hz})$ is $0.45 \mathrm{~mm}$.

The brown dashed curve in Fig. 5 reflects TMD mass m oscillations. The observer can see that the TMD curve is repeating in some way the character of the conveyor damped vibration curve. The peak of the TMD curve is equal to $3.533 \mathrm{~mm}$ at $8.9 \mathrm{~Hz}$. VEHD peak of useful power could be plotted by the solid magenta curve (see Fig. 6). There is the abscissa axis for frequencies in $\mathrm{Hz}$ and the ordinate axis the for peak values of useful power (in $\mathrm{kW}$ ). VEHD useful power is calculated by formula $P(\omega)=0.5 R_{\mathrm{d}} i_{2}$, where $R_{\mathrm{d}}=0.72 R$. The peak of useful power is $1.63 \mathrm{~kW}$ at $10 \mathrm{~Hz}$.

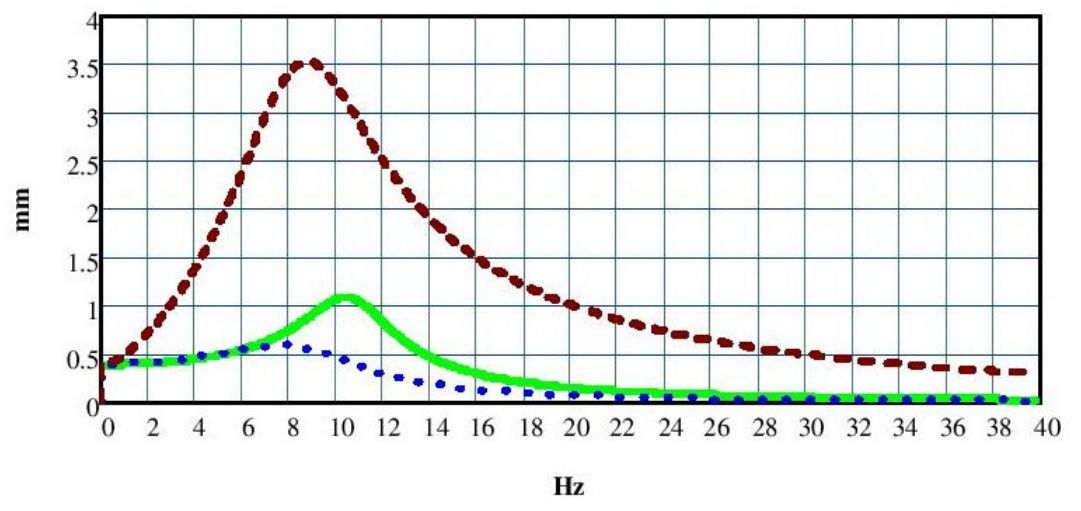

Fig. 5. Theoretical dynamical characteristics for object when VEHD installed 


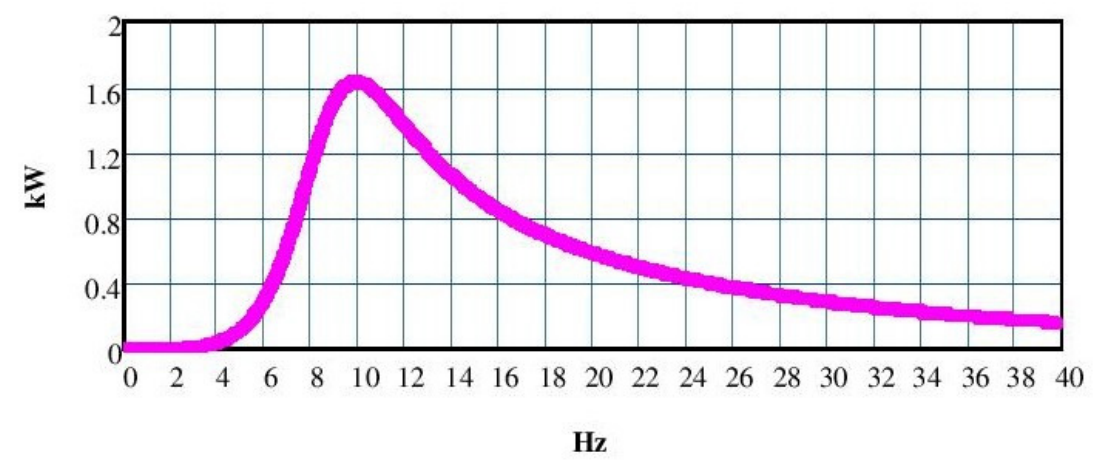

Fig. 6. Theoretical power characteristics for object when VEHD installed

The prototype of VEHD focused on extracting the possibly maximum power from vibrating chassis was designed and fabricated. The design parameters were composed specifically for VEHD mounting at the discharge area vibrating in the range of $0 \mathrm{~Hz}-40 \mathrm{~Hz}$. The selected mass of the fabricated movable TMD part in VEHD was $1 / 4$ of the model mass or $69.75 \mathrm{~kg}$. All other main characteristics were based on the values presented in the modelling case. Four units of VEHD were vertically installed close to the perimeter of the discharge area. The photo of the test rig system master control box incorporating the designed scheme is presented in Fig. 1, (without central computer) in Fig. 7.

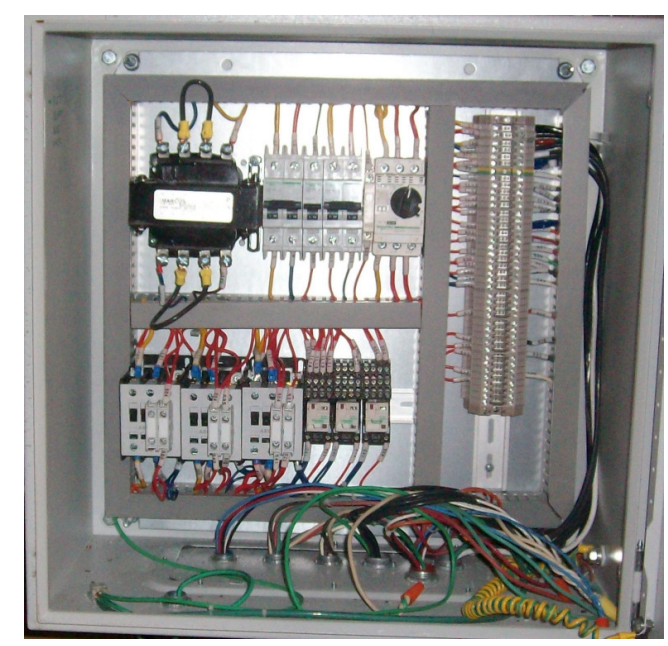

Fig. 7. Master control system box

There is one peak only of $0.5 \mathrm{~mm}$ at $7.9 \mathrm{~Hz}$. The measured combined maximum value of the useful power delivered by four VEHD is equal to $1.59 \mathrm{~kW}$.

Comparison of the values metered during the tests to the data received theoretically shows that deviation of the obtained data from the theoretically predicted is small; and it could be concluded that these results confirm satisfactory compliance of the dynamic and energy properties of the real fabricated VEHD to the theoretically predicted model.

As a result, one can see that the maximal values of amplitude of disturbing vibrations reduce from $1.1 \mathrm{~mm}$ (recorded at $10.8 \mathrm{~Hz}$ ) to $0.5 \mathrm{~mm}$ (recorded at $7.9 \mathrm{~Hz}$ ). It is a dual benefit - reduction of amplitude in 2.2 times and shifting of the resonance frequency to lower magnitudes (from $10.8 \mathrm{~Hz}$ to $7.9 \mathrm{~Hz}$ ). Hence, the overall vibration acceleration is reduced in 4.11 times. These issues provide the increase of effectiveness and accuracy of the arm manipulation. Also, the system can generate for free additional $1.6 \mathrm{~kW}$. The presented VEHD could be considered as a module easy for population at the agricultural engineering practice.

\section{Conclusions}

1. The developed vibration energy harvesting dampers completed with the special control device of the springing element provide an efficient solution for performance improvement of the agricultural belt conveyor-feeder systems. 
2. The provided solution allows to solve multiple problems in the belt conveyor-feeder systems:

- arm's functioning with increased performance and perfect accuracy during outgoing product handling;

- arm's functioning with a minimal energy consumption;

- additional electrical power generation using the suppressed vibrations of the operating belt conveyor-feeder;

- increasing of the lifetime of all systems in operating the belt conveyor-feeder.

3. The proposed approach gives a tool to combat the extensive inertia forces, aerodynamic resistances, wind loads, and other loads, which could be registered during the belt conveyorfeeder systems operation.

\section{Acknowledgements}

This work was supported by the Russian Foundation or Basic Research under the grant No.18-0800168.

\section{References}

[1] Nerubenko G.P., Trunin S.F. Design of robot's drives. Textbook. Publisher: Shipbuilding Institute. Nikolaev. 1985. 41 p. (In Russian)

[2] Нерубенко Г. П., Ватипко Б. А., Щур П. А., Справочник по перегрузочному оборудованию на морском транспорте (The handbook of loading equipment in marine transport). Одесса Маяк 1990, 221 c. (In Russian).

[3] Bograd A., Nerubenko G., Nerubenko C. Energy Harvesting in Vehicle's Drive. Proceedings of the 2nd International Conference of Energy Harvesting, Storage, and Transfer (EHST'18). Niagara Falls, Canada, 2018, Paper No. 112.

[4] Nerubenko G., Bograd A., Kolomier P. Tuned mass dampers as energy harvesters for railways. Proceedings of ISMA 2018 and USD2018. Leuven, Belgium, 2018, pp. 1689-1702.

[5] Nerubenko G., Krupenin V., Nerubenko C. Vehicle Hybrid Free - Piston Engine - Generator. $16^{\text {th }}$ International Scientific Conference "Engineering for Rural Development". Proceedings. Jelgava, Latvia, May 24.-26, 2017. pp. 114-120

[6] Nerubenko et al. "Vibration Energy Harvesting Damper". U.S. Patent Application No. 16/119,346. 08.31, 2018. 